\title{
Studies on a Foam System of Ultralow Interfacial Tension Applied in Daqing Oilfield after Polymer Flooding
}

\author{
Hong-sheng Liu, ${ }^{1}$ Jing-qin Wang, ${ }^{2}$ Li Yang, ${ }^{1}$ Dong-yang Jiang, ${ }^{1}$ Chang-sen Lv, \\ Chang-yu Cui, ${ }^{1}$ and Si-yuan Gao ${ }^{1}$ \\ ${ }^{1}$ Exploration and Development Research Institute of Daqing Oilfield Company Ltd., Daqing 163712, China \\ ${ }^{2}$ Production and Engineering Research Institute of Daqing Oilfield Company Ltd., Daqing 163453, China
}

Correspondence should be addressed to Hong-sheng Liu; liuhs9902@163.com

Received 31 May 2013; Accepted 15 August 2013

Academic Editor: Binod R. Giri

Copyright (C) 2013 Hong-sheng Liu et al. This is an open access article distributed under the Creative Commons Attribution License, which permits unrestricted use, distribution, and reproduction in any medium, provided the original work is properly cited.

In order to study the effects of oil displacement by a foam system of ultralow interfacial tension, the interfacial activities and foam properties of a nonionic gemini surfactant (DWS) were investigated under Daqing Oilfield reservoir conditions. Injection methods and alternate cycle of the foam system were discussed here on the basis of results from core flow experiments. It was obtained that the surface tension of DWS was approximately $25 \mathrm{mN} / \mathrm{m}$, and ultralow interfacial tension was reached between oil and DWS with a surfactant concentration between $0.05 \mathrm{wt} \%$ and $0.4 \mathrm{wt} \%$. The binary system showed splendid foam performances, and the preferential surfactant concentration was $0.3 \mathrm{wt} \%$ with a polymer concentration of $0.2 \mathrm{wt} \%$. When gas and liquid were injected simultaneously, flow control capability of the foam reached its peak at the gas-liquid ratio of $3: 1$. Enhanced oil recovery factor of the binary foam system exceeded $10 \%$ in a parallel natural cores displacement after polymer flooding.

\section{Introduction}

Polymer flooding has entered the stage of successive water flooding in the main layers of Daqing Oilfield. Compared with water flooding, polymer flooding could improve both sweeping volumes and oil displacing efficiencies, resulting in an enhanced recovery factor of $10 \%$. However, $50 \%$ of the geological reserves still remained in the original reservoirs after polymer flooding $[1,2]$. Conflicts in the interlayers and inherent layers were the most influential factors in the development of the main reserves of Daqing Oilfield. Therefore, new methods of enhanced oil recovery were of crucial significance [3].

Foam technologies abroad have focused primarily on the flow control of gases, such as during carbon dioxide flooding and steam flooding $[4,5]$. Some researches concerning foam technology have been conducted in Daqing and Shengli Oilfields, focusing primarily on flow control and enhanced recovery efficiency $[6,7]$. Results of these studies indicated that foam was a viscoelastic fluid with a larger flow resistance than polymer. Therefore, foam flooding appeared to have great potential in enhanced oil recovery (EOR) [8].

In order to research the feasibility of foam flooding after polymer flooding in Daqing Oilfield, interfacial activities, foam stability, foam flow properties, and oil displacement of a nonionic gemini surfactant were investigated under Daqing Oilfield reservoir conditions. Results from this research could provide important process parameters for drafting foam flooding schemes.

\section{Materials and Methods}

The oil and water were Daqing crude oil and oilfield sewage. Two different partially hydrolyzed polyacrylamides (HPAM), with the molecular weight of 16 and 25 million, were provided by the Daqing Refinery Company. The surfactant was a nonionic gemini surfactant (DWS). The man-made homogeneous cores were purchased from the Northeast Petroleum University. The natural cores were part of the major reservoirs 


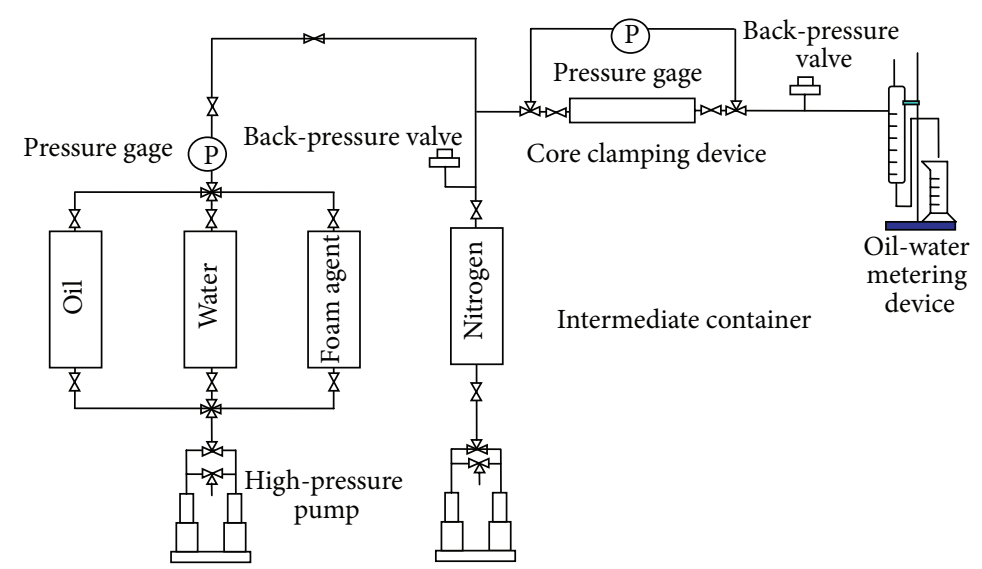

FIGURE 1: Schematic diagram of the foam displacement and flow control instruments.

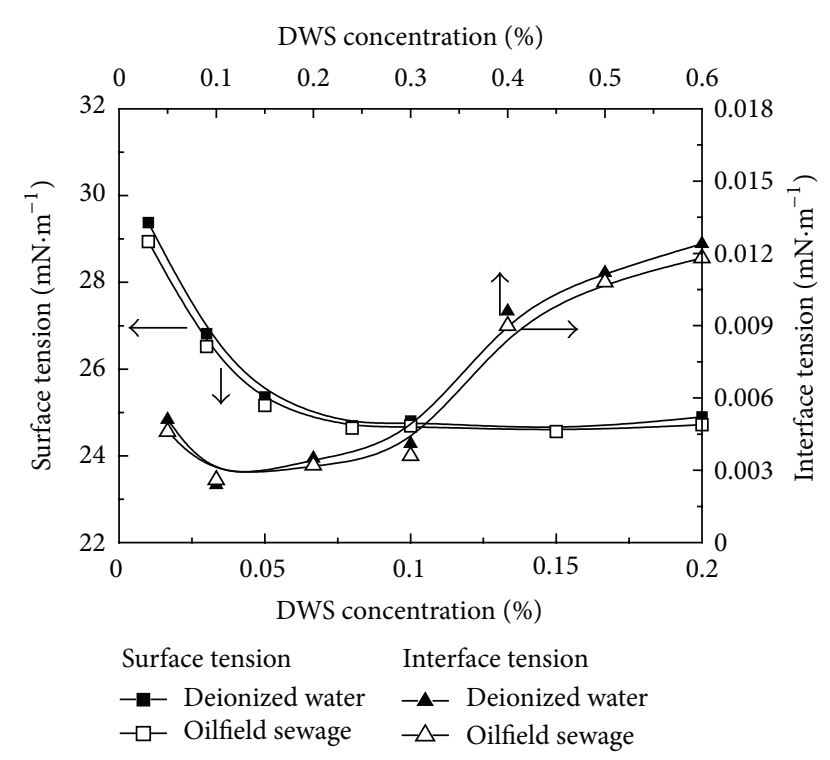

FIGURE 2: Surface and interfacial tensions of DWS.

of the Daqing Oilfield. The TX500C spinning drop interface tensiometer was purchased from Bowing Industry Company in America. The foam scanner was purchased from I.T. Concept in France. The foam displacement and flow control instruments were provided by the Jiangsu Huayan Petroleum Apparatus Company (Figure 1).

\section{Results and Discussion}

\subsection{Properties of Foam Agent}

3.1.1. Surface and Interfacial Tensions. Surface and interfacial tensions are not only important indicators of surfactant activity but also some of the most important parameters in chemical flooding. The surface and interfacial tensions of DWS were shown in Figure 2. It was clear that surface tension of DWS decreased as its concentration increased. According to the curves, the critical micelle concentration of DWS was

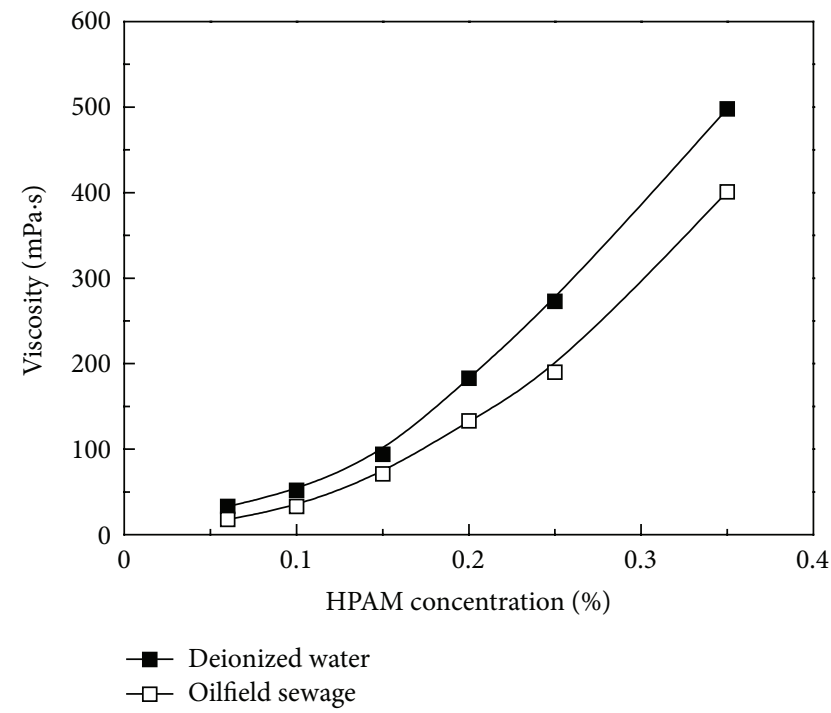

FIGURE 3: Viscosities of DWS in HPAM system.

about $0.08 \mathrm{wt} \%$, and the surface tension of DWS then was approximately $25 \mathrm{mN} / \mathrm{m}$, which was close to the theoretical minimum surface tension of hydrocarbon surfactants. In short, the surface activity of DWS was very good. The interfacial tensions of DWS in different concentrations were measured. Results indicated that an ultralow interfacial tension was reached between oil and DWS in the concentration range of $0.05 \mathrm{wt} \%$ to $0.4 \mathrm{wt} \%$, which further implied the potential of enhancing oil displacement efficiency. Because DWS was a nonionic surfactant, inorganic salts had less influences on the surface and interfacial tensions of DWS.

3.1.2. Viscosity Properties. Viscosities of foam systems which are also one of the most influential parameters in chemical EOR. Viscosities of DWS in a polymer system were shown in Figure 3. Molecular weight of the HPAM polymer was 25 million, and concentration of DWS was $0.3 \mathrm{wt} \%$. It was observed that viscosities of the binary system increased as the polymer concentration went up. Compared with the 


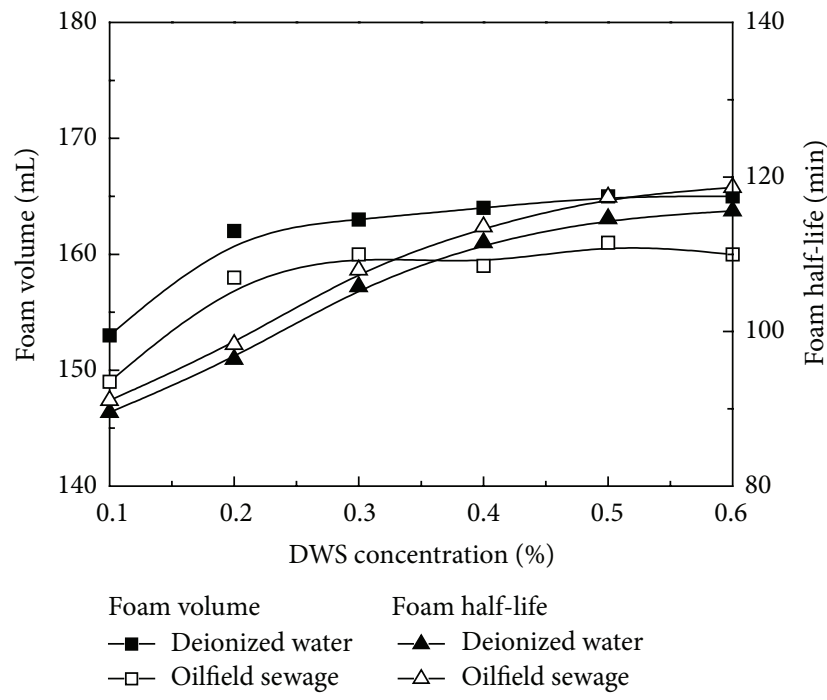

(a)

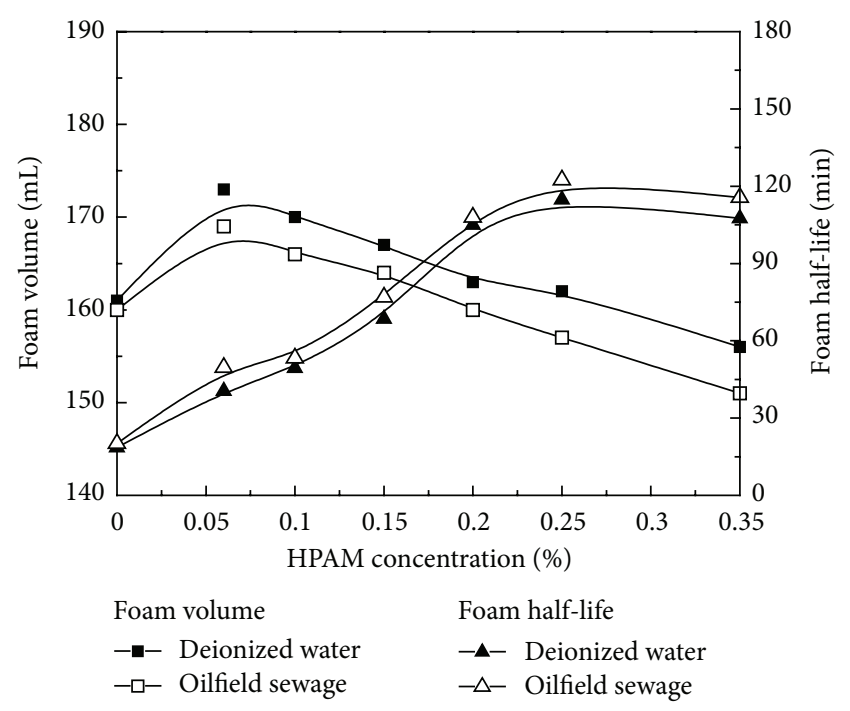

(b)

FIGURE 4: Foam volumes and stability of DWS in HPAM systems.

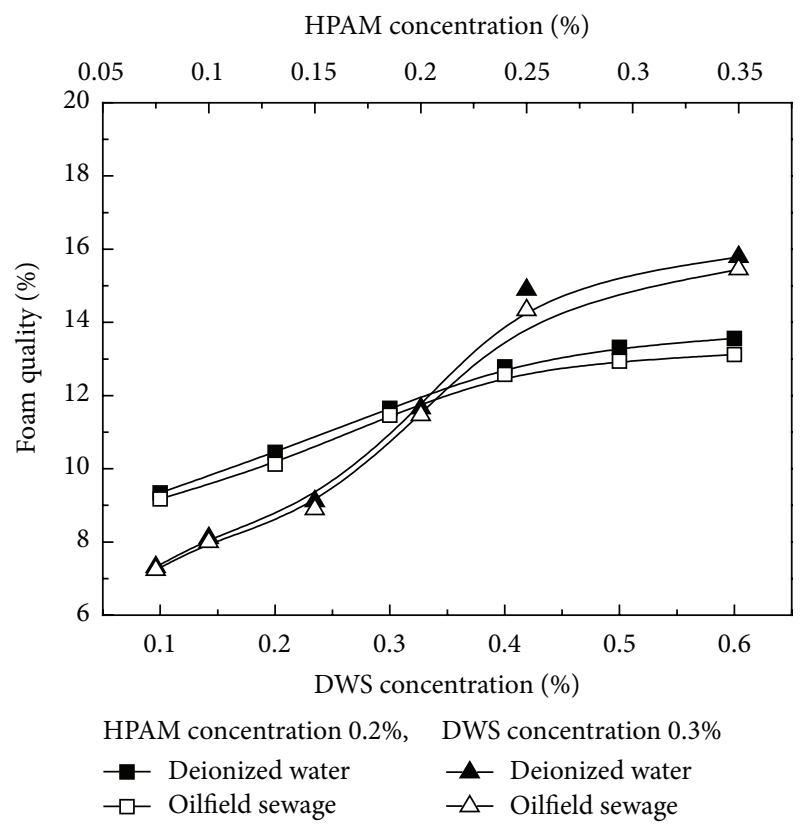

FIGURE 5: Foam quality of DWS in HPAM system.

viscosities in deionized water, viscosities of the binary system reduced in brine.

3.1.3. Foam Properties. Foam volumes and stability of a binary foam agent system were tested, and the results were shown in Figure 4. When the molecular weight and concentration of the HPAM polymer were 25 million and $0.2 \mathrm{wt} \%$, foam volumes and stability of the binary system increased as the concentration of DWS was added. When the DWS concentration exceeded $0.2 \mathrm{wt} \%$ in sewage, foam volumes of the binary system tended to become steady. The same happened in deionized water when the DWS concentration exceeded $0.3 w t \%$.

When molecular weight of the HPAM polymer was 25 million and concentration of DWS was $0.3 \mathrm{wt} \%$, foam volumes of the binary system first increased as the polymer concentration rose, and then it decreased. Foam stability of the binary system increased with the polymer concentration and became steady when polymer concentration exceeded $0.2 \mathrm{wt} \%$. It was analyzed that the optimum foam agent system should have a DWS concentration of $0.3 \%$, polymer molecular weight of 25 million, and polymer concentration of $0.2 \mathrm{wt} \%$. In inorganic salt solution, foam volumes of the binary system reduced, but foam stability of the binary system slightly increased.

Foam quality of DWS in polymer system was shown in Figure 5. When HPAM molecular weight was 25 million, foam quality of DWS in polymer system first increased as concentration of DWS or HPAM increased, and then it became steady when DWS concentration exceeded $0.4 \mathrm{wt} \%$ or polymer concentration exceeded $0.2 \mathrm{wt} \%$. Trend of the foam quality of the binary system was consistent with that of the foam half-life. Foam quality of the binary system slightly decreased in inorganic salt solution.

3.1.4. Adsorption Properties. The adsorption properties of DWS were studied, and results were shown in Table 1. The interfacial tensions of DWS decreased after adsorption in cores at the concentration less than $0.3 \mathrm{wt} \%$. But when DWS concentration exceeded $0.3 \%$, interfacial tensions of DWS increased after adsorption in cores. Foam volumes of DWS were not influenced by core adsorption. Meanwhile, foam half-life of DWS increased after adsorption in cores. Because DWS was a nonionic surfactant, its adsorption in cores was quite small [9]. Therefore, the interfacial tensions and foam properties of DWS decreased slightly after adsorption in cores. Some tiny matter suspended in the solution after 
TABLE 1: Properties of DWS after adsorption in cores.

\begin{tabular}{llccccc}
\hline \multicolumn{2}{c}{ DWS concentration (\%) } & 0.1 & 0.2 & 0.3 & 0.4 & 0.5 \\
\hline \multirow{2}{*}{ Surface tension (mN/m) } & Original solution & 0.0056 & 0.0045 & 0.0034 & 0.0084 & 0.0112 \\
& After adsorption & 0.0078 & 0.0047 & 0.0035 & 0.0032 & 0.0053 \\
\hline \multirow{2}{*}{ Foam volume (mL) } & Original solution & 164 & 163 & 161 & 165 & 165 \\
& After adsorption & 156 & 158 & 160 & 161 & 36.4 \\
\multirow{2}{*}{ Foam stability (min) } & Original solution & 30.1 & 32.1 & 35.1 & 36.1 \\
& After adsorption & 35.1 & 38.5 & 46.2 & 48.1 \\
\hline
\end{tabular}

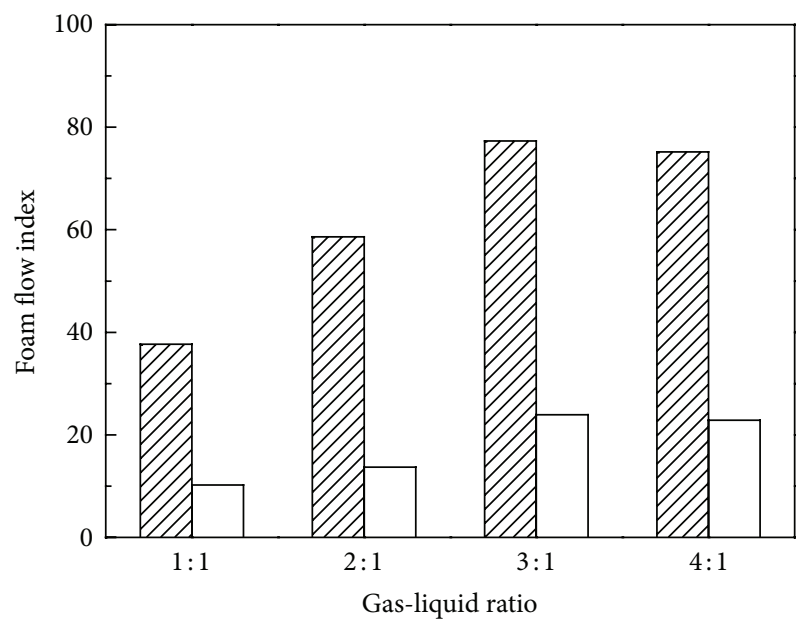

QZIA Foam resistance factor

$\square$ Foam residual resistance factor

FIGURE 6: Effect of gas-liquid ratio on foam flow resistance.

adsorption in cores, which was helpful to improve foam stability [10].

\subsection{Properties of Foam Flow}

3.2.1. Effects of Gas-Liquid Ratio on Foam Flow Resistance. Control capability of foam flow was studied under different gas-liquid ratios, and results were shown in Figure 6. In the research, a binary foam agent system was applied. Molecular weight and concentration of polymer HPAM were 25 million and $0.2 \mathrm{wt} \%$, and DWS concentration was $0.3 \mathrm{wt} \%$. Alternate period of the gas-liquid mixture was 0 , and permeability of the man-made homogeneous cores was about $0.8 \mu \mathrm{m}^{2}$.

The resistance and residual resistance factors of the foam first increased as the gas-liquid ratio went up, but then they decreased. When the gas-liquid ratio was $3: 1$, control capability of the foam flow reached its peak. When the gasliquid ratio was below $3: 1$, there was enough gas in the porous media as the gas-liquid ratio increased, which resulted in lots of foam and increased plug capacity of foam in cores. And the resistance and residual resistance factors of the foam increased. As the gas-liquid ratio continued to increase, gas content in porous media also increased. On the one hand, more foam was generated in the porous media, which helped to plug the large pores in the cores. On the other hand,

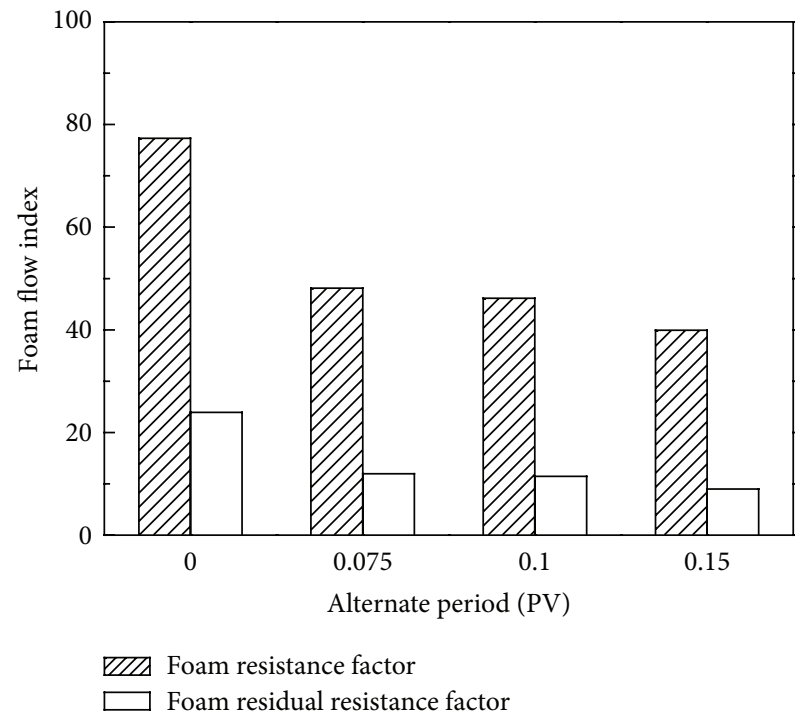

FIGURE 7: Effects of the gas-liquid alternate period on foam flow resistance.

the liquid film of the foam becomes thinner, decreasing the stability of the foam and causing it to break down more easily. A gas-liquid ratio of more than 3:1 was too large, making it difficult for the foam to be produced in the porous media and even resulting in gas channeling. The plug capacity of the foam decreased, causing the resistance and residual resistance factors of the foam to decline.

\subsubsection{Effects of the Gas-Liquid Alternate Period on Foam} Flow Resistance. Gas-liquid alternate period of foam was researched, and results were shown in Figure 7. In this investigation, a binary foam agent system was applied. Molecular weight and concentration of polymer HPAM were 25 million and $0.2 \mathrm{wt} \%$, and DWS concentration was $0.3 \mathrm{wt} \%$. The gasliquid ratio was $3: 1$, and permeability of the man-made homogeneous cores was about $0.8 \mu \mathrm{m}^{2}$.

When the gas-liquid alternate period was 0 , control capability of the foam flow reached its peak. The resistance and residual resistance factors of the foam were the largest. Resistance and residual resistance factors of the foam decreased as the gas-liquid alternate period increased. When alternate period increased, separate displacements of the gas and liquid become obvious in cores, which were unfavorable for bubble forming and reduced the foam flow resistance. 
TABLE 2: Foam flooding results of a parallel natural core.

\begin{tabular}{|c|c|c|c|c|c|c|c|}
\hline Sort & Core number & $\begin{array}{c}\text { Gas } \\
\text { permeability } \\
\left(\mu \mathrm{m}^{2}\right)\end{array}$ & $\begin{array}{c}\text { Oil saturation } \\
(\%)\end{array}$ & $\begin{array}{l}\text { Water flooding } \\
\text { EOR }(\%)\end{array}$ & $\begin{array}{l}\text { HPAM flooding } \\
\text { EOR (\%) }\end{array}$ & $\begin{array}{c}\text { Foam flooding } \\
\text { EOR }(\%)\end{array}$ & Total EOR (\%) \\
\hline \multirow{3}{*}{1} & $\mathrm{~L}-20$ & 0.886 & 69.3 & 50.6 & 9.6 & 9.6 & 69.8 \\
\hline & $\mathrm{L}-23$ & 0.316 & 67.2 & 46.3 & 7.8 & 11.8 & 65.9 \\
\hline & Average & & & 48.5 & 8.7 & 10.7 & 67.9 \\
\hline \multirow{3}{*}{2} & $\mathrm{~L}-54$ & 0.714 & 63.0 & 43.8 & 13.1 & 8.9 & 65.8 \\
\hline & L-59 & 0.353 & 65.4 & 46.1 & 6.2 & 12.2 & 64.5 \\
\hline & Average & & & 45.0 & 9.6 & 10.5 & 65.1 \\
\hline
\end{tabular}

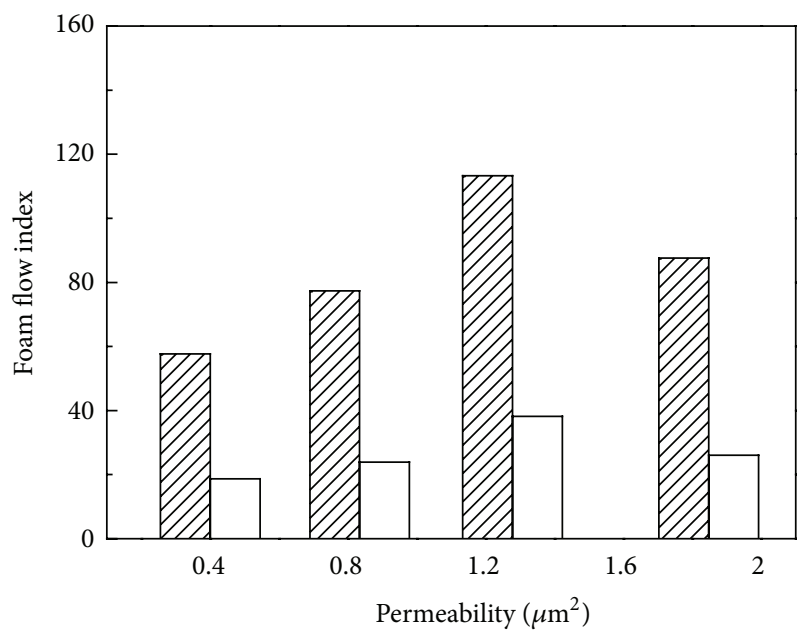

VIIA Foam resistance factor

$\square$ Foam residual resistance factor

FIGURE 8: Effects of core permeability on foam flow resistance.

3.2.3. Effects of Core Permeability on Foam Flow Resistance. Effects of core permeability on foam flow resistance were shown in Figure 8. In this research, a binary foam agent system was applied. Molecular weight and concentration of polymer HPAM were 25 million and $0.2 \mathrm{wt} \%$, and DWS concentration was $0.3 \mathrm{wt} \%$. The gas-liquid ratio was $3: 1$, and alternate period was 0 .

The resistance and residual resistance factors of the foam first increased as core permeability rose, but then it decreased. When the core permeability was about $1.2 \mu \mathrm{m}^{2}$, control capability of the foam flow reached its peak. Results indicated that there was a matching relationship between the mobility control of the foam system and the core permeability. Flooding controls in cores of different permeability should be improved by different foam systems.

3.3. Foam Flooding Results of a Parallel Natural Core. In order to further verify the displacing efficiency of foam flooding, experiments were conducted in a parallel core, and results were shown in Table 2. In the experiments, the core was first flooded by HPAM with the molecular weight and concentration of 16 million and $0.1 \mathrm{wt} \%$ and then flooded by a binary foam agent system. For the foam agent system,
Molecular weight and concentration of polymer HPAM were 25 million and $0.2 \mathrm{wt} \%$, and DWS concentration was $0.3 \mathrm{wt} \%$. The gas-liquid ratio was $3: 1$, and alternate period was 0 .

Enhanced recovery factor for the binary foam system exceeded $10 \%$. Because the foam blocked the highpermeability pores effectively and enlarged sweeping volumes, it could move forward in cores homogeneously. Meanwhile, the remaining oil could be emulsified to form small oil droplets, which could enter the membrane of the foam liquid. Foam containing these oil droplets moved over a certain distance, and then the foam was broken to release the oil droplets. Subsequent foam repeated the process. It was found that the displacing efficiency of foam was better than that of polymer flooding.

\section{Conclusions}

(1) The surface tension of DWS was approximately $25 \mathrm{mN} / \mathrm{m}$. Ultralow interfacial tension was reached between oil and DWS with a surfactant concentration between $0.05 \mathrm{wt} \%$ and $0.4 \mathrm{wt} \%$. The binary system showed splendid foam performances, and the preferential surfactant concentration was $0.3 \mathrm{wt} \%$ with a polymer concentration of $0.2 \mathrm{wt} \%$.

(2) When gas and liquid were injected simultaneously, flow control capability of the foam reached its peak at the gas-liquid ratio of $3: 1$. Enhanced oil recovery factor of the binary foam system exceeded $10 \%$ in a parallel natural core displacement after polymer flooding.

\section{Acknowledgment}

The authors want to thank the Major Project of Chinese National Program of Fundamental Research and Development for its financial support (Grant no. 2005CB221300).

\section{References}

[1] D. M. Wang, J. C. Cheng, J. Z. Wu, and G. Wang, "Application of polymer flooding technology in Daqing Oilfield," Acta Petrolei Sinica, vol. 26, no. 1, pp. 74-78, 2005.

[2] D. Wang, R. S. Seright, Z. Shao, and J. Wang, "Key aspects of project design for polymer flooding at the Daqing Oil Field," 
SPE Reservoir Evaluation and Engineering, vol. 11, no. 6, pp. 1117$1124,2008$.

[3] F. L. Zhao, Y. F. Wang, C. L. Dai, S. Ren, and C. Jiao, "Techniques of enhanced oil recovery after polymer flooding," Journal of China University of Petroleum, vol. 30, no. 1, pp. 86-89, 2006.

[4] S. Tortopidis and D. C. Shallcross, "Carbon dioxide foam flood studies under Australian reservoir conditions," in Proceedings of the Asia Pacific Oil \& Gas Conference, SPE 28811, pp. 655-665, November 1994.

[5] S. I. Chou, "Conditions for generating foam in porous media," in Proceedings of the SPE Annual Technical Conference and Exhibition, SPE 22628, pp. 353-364, October 1991.

[6] H. Liu, P. Ye, Y. Liu, and X. Wang, "Nitrogen foam injection technique and its application in reservoirs with high water cut," Acta Petrolei Sinica, vol. 31, no. 1, pp. 91-95, 2010.

[7] Z. B. Shao, L. J. Sun, and H. S. Liu, "The study of high-pressure foam combination flooding after polymer flooding," Petroleum Geology \& Oilfield Development in Daqing, vol. 30, no. 2, pp. 140-144, 2011.

[8] D. Benjamin, A. Miguel, and G. Francois, "Anti-inertiral lift in foams: a signature of the elasticity of complex fluids," Physical Review Letters, vol. 95, no. 16, pp. 168-303, 2005.

[9] M. J. Rosen and X. Y. Hua, "Surface concentrations and molecular interactions in binary mixtures of surfactants," Journal of Colloid and Interface Science, vol. 86, no. 1, pp. 164-172, 1982.

[10] T. S. Horozov, "Foams and foam films stabilised by solid particles," Current Opinion in Colloid and Interface Science, vol. 13, no. 3, pp. 134-140, 2008. 

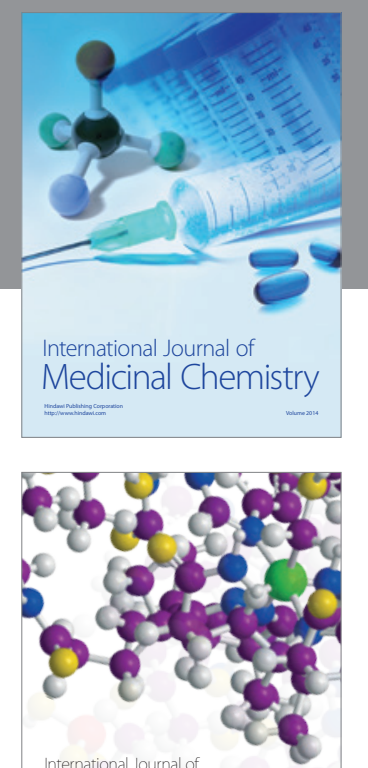

\section{Carbohydrate} Chemistry

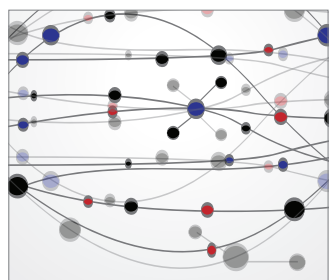

The Scientific World Journal
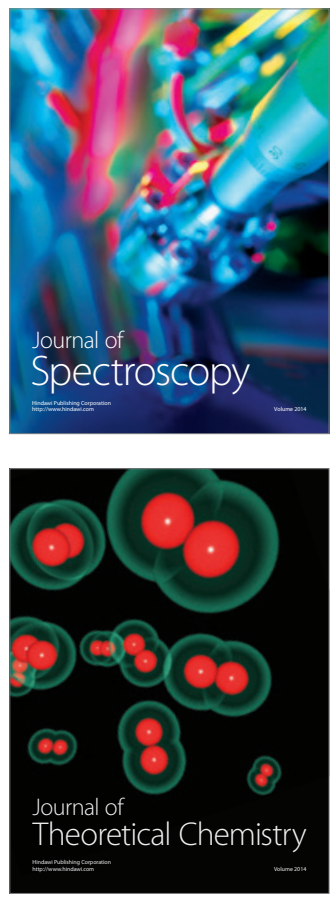
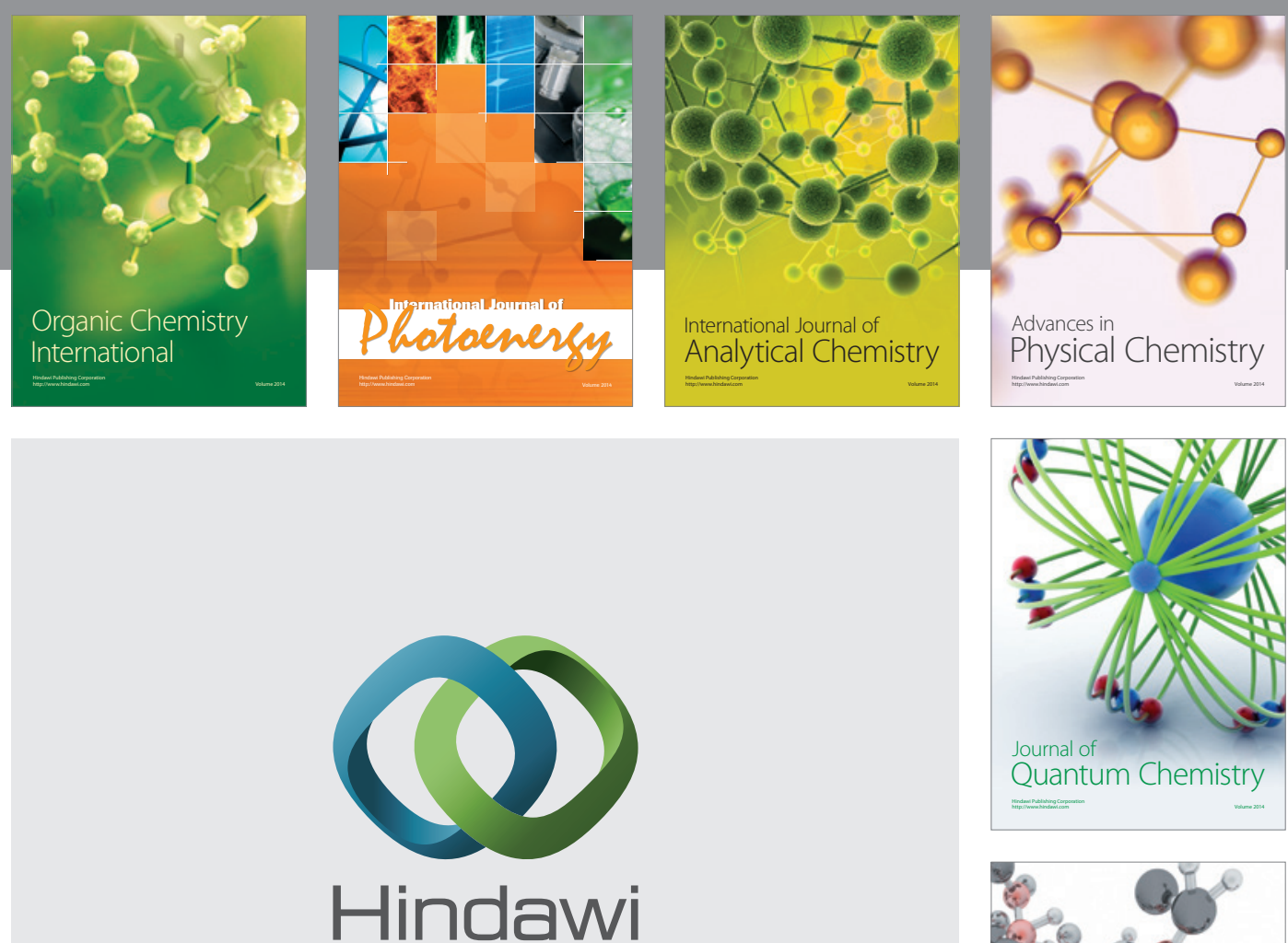

Submit your manuscripts at

http://www.hindawi.com

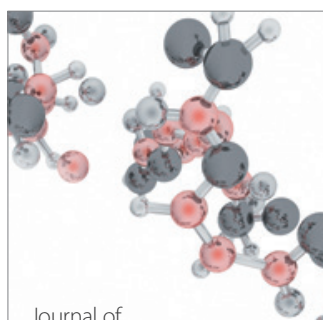

Analytical Methods

in Chemistry

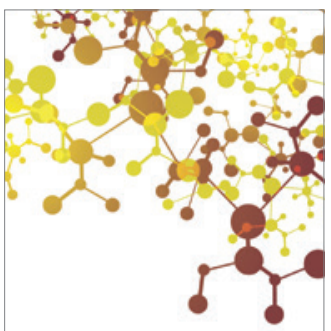

Journal of

Applied Chemistry

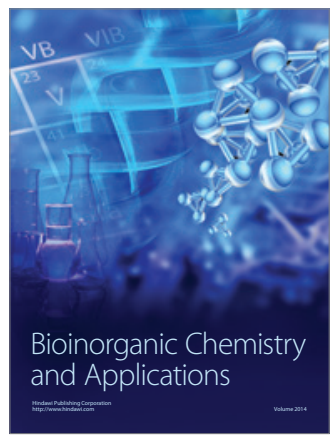

Inorganic Chemistry
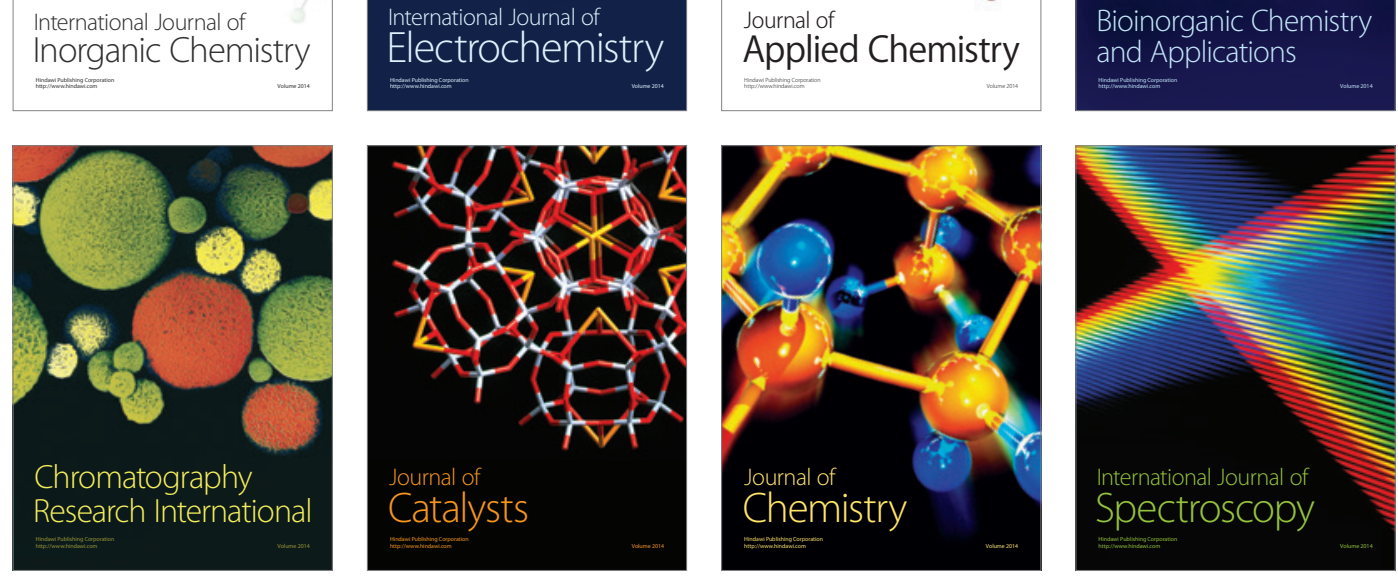